\title{
Diagnostic Wind Model Initialization over Complex Terrain Using the Airborne Doppler Wind Lidar Data
}

\author{
Yansen Wang*,a, Chatt Williamson ${ }^{\mathrm{a}}$, Giap Huynh ${ }^{\mathrm{a}}$, David Emmitt ${ }^{\mathrm{b}}$ and Steve Greco ${ }^{\mathrm{b}}$ \\ ${ }^{a}$ US Army Research Laboratory, AMSRD-ARL-CI-ED, Adelphi, MD 20783, USA; ${ }^{b}$ Simpson Weather Associates, \\ Charlottesville, VA 22902, USA
}

\begin{abstract}
An initialization method using airborne Doppler wind lidar data was developed and evaluated for a massconsistent diagnostic wind model over complex terrain. The wind profiles were retrieved from the airborne lidar using a conical scanning scheme and a signal processing algorithm specifically designed for the airborne lidar system. An objective data analysis method in complex terrain was then applied to those wind profiles to produce a three-dimensional wind field for model initialization. The model results using the lidar data initialization were compared with independent surface weather observational data and profiles from a microwave radar wind profiler. The model was previously run for a small domain with simple terrain where comparisons with a surface observation array showed that the model performed well in a strong wind condition. For the more complex terrain in the Salinas valley, the model evaluation with a limited number of observations indicated that the diagnostic wind model with airborne Doppler lidar data also produced a reasonably good wind field in moderate to strong wind conditions. However, caution must be stressed for weak wind conditions in which the flow is thermally driven as the mass-consistent diagnostic wind model is not equipped to handle such cases. The effect of the lidar wind profile density over a simulation domain was also investigated for practical applications. The results indicate that about a half dozen lidar wind profiles would be adequate for a 20 by $20 \mathrm{~km}$ complex terrain domain with fairly uniform and moderate wind conditions.
\end{abstract}

Keywords: Airborne doppler wind lidar, diagnostic wind model for complex terrain, model initialization using lidar data.

\section{INTRODUCTION}

Doppler wind lidars (DWL) have been used to observe the atmospheric boundary layer (ABL) circulations as the technology has been improved and refined during several decades of studies and applications. Many ABL studies have applied ground-based DWL to monitor the circulations and aerosols of the boundary layer. Examples include the investigation of thermal-driven flows such as mountainvalley wind $[1,2]$, and the land-sea breeze $[3,4]$. Since the DWL can be operated in scanning mode to retrieve the wind profiles at lower and higher altitudes at the same time, the ground-based DWL has also been used to study the nocturnal low-level jet and turbulence interactions over complex terrain $[5,6]$ and over an urban environment $[7,8]$. DWL retrieved wind profiles have also been used to assimilate observational data into sophisticated atmospheric boundary layer large-eddy simulation models $[9,10]$. These studies have proven that ground-based lidar is an effective and accurate remote sensing technology for investigating the multi-scale ABL flow, especially for its capability to scan the winds at different locations in a very short time window. Recently, airborne DWL have also been developed and tested for ABL wind measurement over significantly larger areas. For example, some important spatial structures of organized eddies [11] and coastal jet [12] were captured by an airborne DWL. Weissmann et al. [13] have concluded that it is feasible and valuable to use airborne DWL data for

*Address correspondence to this author at the U.S. Army Research Laboratory, RDRL-CIE-D, Adelphi, MD 20783-1197, USA;

Tel: 301-394-1310; Fax: 301-394-1478; E-mail: ywang @arl.army.mil mesoscale model data assimilation over the data sparse Atlantic region. One major advantage of the airborne DWL is that it can not only capture the spatial heterogeneity of the ABL flow over a large area in a short duration, but also can be set up quickly for the targeted observations in a data sparse area.

High resolution wind field data in both space and time are often required for many applications in the ABL. While increasing the resolution, or nesting a large eddy simulation model within a mesoscale weather model is a potential solution to meet this requirement, it remains impractical for near real-time applications in the foreseeable future due to limitations in computational power. For applications with high spatial (from several meters to hundreds of meters) and temporal (several minutes) resolutions requiring rapid results, mass-consistent diagnostic wind models are currently widely used due to their low demand on computational power and reasonable accuracy. In the early development of the diagnostic wind model, the initial wind field was mostly obtained from very few surface weather stations or tower anemometer observations [14-19]. As the domain becomes larger and more heterogeneous, the model requires more representative data from multiple stations to initialize the model in order to capture the spatial variations. The upper level flow information is also important because the wind field often has large directional and speed changes between the surface and the upper levels of the ABL. In more recent years, the use of the coarser, mesoscale predicted wind profiles in diagnostic wind models has become common practice. Two such examples are the Hazard Prediction and 
Assessment Capability (HPAC) [20] and California Meteorological Model (CALMET) [21] systems.

One of the problems in using mesoscale weather model results for diagnostic model initialization is that the weather prediction model results often have time lags for weather systems passage and the microscale variations of the wind field may not be contained in the mesoscale model results. Since the microscale mass-consistent diagnostic model is designed to simulate a mean wind field in high resolution and for a short period of time, its accuracy is largely dependent on good initial conditions. The accurate initial wind is hard to obtain, especially for a large model domain with heterogeneous morphology. As a result, multiple wind profiles are necessary to account for the flows induced by land surface heterogeneity. Modern airborne DWL may have the potential to fill this void since it can cover the interested area in a relatively short time and with reasonable accuracy. The objective of this research is to investigate the feasibility using the airborne DWL observed wind profiles for initialization of a diagnostic wind model in complex terrains. At the same time, a model initialization method using the airborne DWL data will be developed and evaluated for practical applications in complex terrain.

\section{MATERIAL AND METHODS}

\section{Airborne Doppler Wind Lidar and Wind Profile Retrieval}

The airborne DWL data used in this study was described in detail in [11] and [22]. Over the past 10-15 years, the Integrated Program Office (IPO) of NPOESS (National Polar-orbiting Operational Environmental Satellite System), with an eye to eventual deployment in space, has funded the development and deployment of an airborne coherent DWL, initially mounted in a Navy Twin Otter aircraft to conduct a variety of investigations. Since 2002, under the direction of Simpson Weather Associates (SWA), operated by the Navy's Center for Interdisciplinary Remotely Piloted Research Studies (CIRPAS) and under support of the IPO, ONR and ARO , the airborne DWL has flown more than 150 hours of atmospheric missions with most of that over the Pacific Ocean and within $50 \mathrm{~km}$ of the shore.

The basic characteristics of the TODWL (Twin Otter Doppler Wind Lidar) are listed in Table $\mathbf{1}$. The lidar is a 2 micron coherent system built by Coherent Technologies, Inc. A defining capability of the TODWL is the ability to profile above and below the flight level. This is possible because the lidar includes a bi-axis scanner mounted on the side door of the aircraft that allows vertical soundings of the wind profile above and below the aircraft and also takes data with horizontal or vertical perspectives. A dedicated internal navigation GPS system was installed on the transceiver to eliminate problems associated with aircraft flexing and data delays and a chiller is used to cool the laser, accounting for most of a $1.5 \mathrm{KW}$ power requirement. At the nominal cruise speed of $50 \mathrm{~m} / \mathrm{s}$, a wind profile can be obtained every 750 800 meters. The scanner can also be pointed directly nadir (adjusted for aircraft pitch and roll). In the nadir setup, vertical motions of the surface and atmosphere can be observed to within $0.1 \mathrm{~ms}^{-1}$ accuracy. The range resolution depends upon the backscatter structure. Using a sliding range gate in the processing 25-50 meter vertical resolution was achieved. In the case of the water or earth surface, the height resolution is better than 10 meters. One feature that distinguishes this airborne Doppler lidar from most others is the side mounted two-axis scanner which allows conical scans above, ahead and below the aircraft.

Table 1. Characteristics of the TOWDL System

\begin{tabular}{|l|l|}
\hline Wavelength (microns) & 2.05 (eye safe) \\
\hline Energy per pulse (mJ) & $2-3$ \\
\hline $\begin{array}{l}\text { Pulse repetition } \\
\text { frequency (Hz) }\end{array}$ & 500 \\
\hline Scanner & 2 axis $(+-120 ;+$ - 30) \\
\hline Range resolution (meters) & $50-100$ \\
\hline $\begin{array}{l}\text { LOS measurement } \\
\left.\text { accuracy (ms }{ }^{-1}\right)\end{array}$ & $\begin{array}{l}<.05 \text { per single shot with ground } \\
\text { calibration }\end{array}$ \\
\hline $\begin{array}{l}\text { Wind component } \\
\left.\text { accuracy (ms }{ }^{-1}\right)\end{array}$ & $\begin{array}{l}\mathrm{u}, \mathrm{v}, \mathrm{w}<.1 \text { nominal using a } 30 \text { degree VAD } \\
\text { LAHDSA }\end{array}$ \\
\hline $\begin{array}{l}\text { Aerosol backscatter } \\
\text { threshold sensitivity }\end{array}$ & Range dependent: $\sim 10-08 \mathrm{~m} \mathrm{sr}^{-1}$ at $10 \mathrm{~km}$ \\
\hline $\begin{array}{l}\text { Nominal range } \\
\text { insensitivity (km) }\end{array}$ & $\begin{array}{l}\text { Aerosol dependent: nominal } 15-20 \mathrm{~km} \text { in } \\
\text { PBL and 2-5 km above PBL }\end{array}$ \\
\hline
\end{tabular}

The data used in this paper was collected on February 21 2003 near Monterey, CA. During this day, the TODWL was flown for a period of 4 hours with the flight pattern shown in Fig. (1). The wind profiles were retrieved from a downward conical scan with 30 degree azimuth intervals using a volume velocity processing method $[11,22]$. Each profile was taken within a 30 second time window yielding a complete $u, v, w$ profile every $1.5 \mathrm{~km}$. Each vertical profile stretched from the surface to 2500 meters height with a vertical resolution of 50 meters. The retrieval method is very similar to the original Velocity Azimuth Display (VAD) devised by Browing and Wexler [23] with an extensive data preprocessing scheme for the moving platform over complex terrain added.

The DWL observes the wind by tracking the frequency shift information from the laser beam backscattering of a moving aerosol parcel. The radial velocity is then inverted from the Doppler shift signal. The signal from the TODWL was processed using an algorithm named Lidar Attitude and Height Determination and Signal Search Algorithm (LAHDSA). In LAHDSA, the aircraft induced pointing and lidar beam pointing errors are corrected, the terrain effects are treated with spectral peak threading, and the terrain heights accounted for in the VAD. The retrieved wind profiles are compared to the microwave sounder at Fort Ord in California (Fig. 2). The profiles are generally in good agreement, although the difference is large from 1.5 to $2 \mathrm{~km}$ height. The direction measurements between the two instruments agree well with less than 20 degree differences. More detailed description of the TODWL system and its performance tests can be found in Emmitt et al. [11] and Greco and Emmitt [22].

\section{Brief Description of 3DWF Model System}

The 3DWF (3-Dimensional Wind Field) model was developed at the U.S. Army Research Laboratory over the 


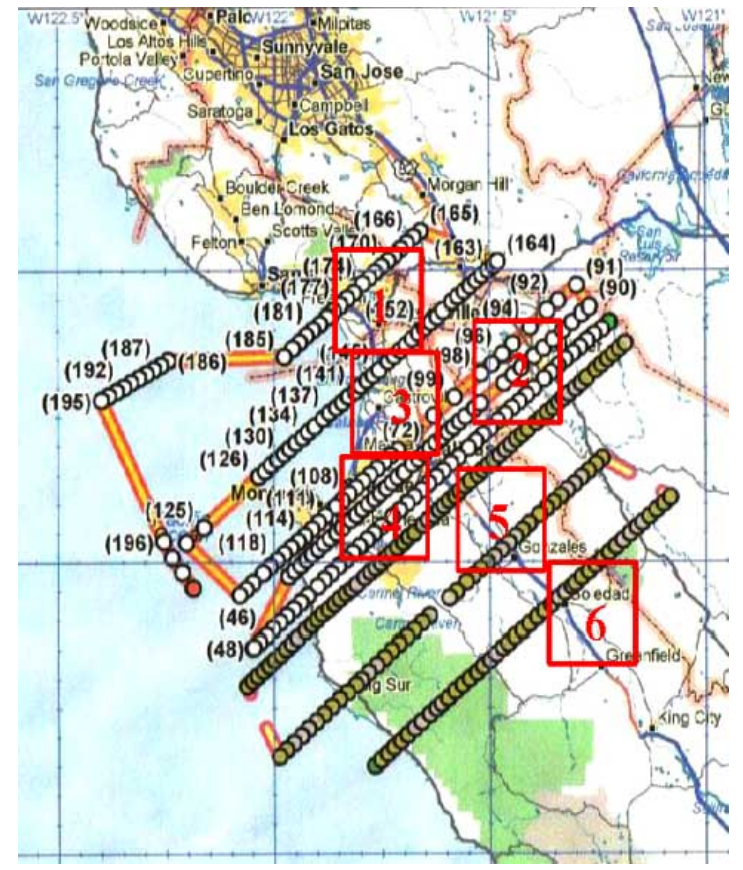

Fig. (1). TOWDL flight tracks 2200 UTC 21 Feb 2003 to 0216 UTC 22 Feb 2003. Each oval represents a retrieved wind profile. The numbered squares are the 3DWF simulation domains for this study.

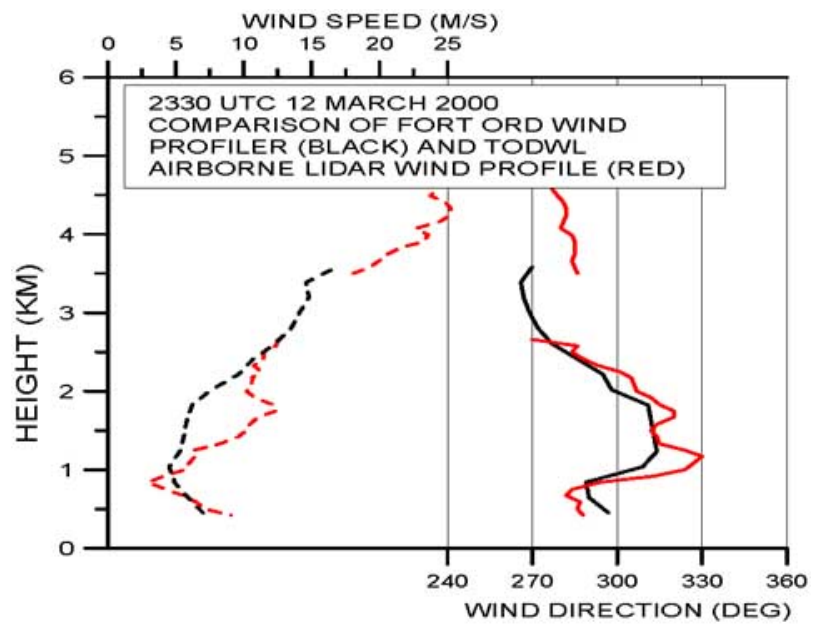

Fig. (2). A comparison of the TODWL retrieved wind speed and direction profiles with the observations from a radar wind profiles located at the Fort Ord.

last several years. It is based on the mass conservation principle, which eliminates the divergence in a flow field. That is, given a limited number of observations or coarsely modeled wind profiles over complex terrain, the wind field is physically interpolated in such way that the mass conservation is satisfied. Mathematically, it is a minimization problem between observed and modeled velocity values using the mass conservation as a constraint. The problem in the Cartesian coordinate can be expressed as the following functional $[14,15]$

$$
\begin{aligned}
& E(u, v, w, \lambda)= \\
& \int_{V}\left[\beta_{1}^{2}\left(u-u^{0}\right)^{2}+\beta_{1}^{2}\left(v-v^{0}\right)^{2}+\beta_{2}^{2}\left(w-w^{0}\right)^{2}+\lambda\left(\frac{\partial u}{\partial x}+\frac{\partial v}{\partial y}+\frac{\partial w}{\partial z}\right)\right] d x d y d z
\end{aligned}
$$

where $x, y$ are the horizontal coordinates, $z$ the vertical coordinate, $u^{0}, v^{0}, w^{0}$ the initial observed velocity components, $u, v, w$ the modeled velocity components, $\lambda$ the Lagrange multiplier, and $\beta_{l}, \beta_{2}$ Gauss precision moduli, which are the wind vector partitioning factors in the horizontal and vertical directions respectively.

In order to simulate the flows in both complex terrain and urban, we have chosen the Cartesian coordinate frame. The advantage of this coordinate system is that it can handle steep variations of the terrain without smoothing out surface features such as a building or very steep topography. In this model, the flows in forests and near the buildings are parameterized. Detailed description of the original 3DWF and several test results can be found in $[24,25]$. However, significant progresses have been made in 3DWF recently [26] to improve both the accuracy and numerical efficiency. The improvements include the following: (1) a new boundary capture method has been implemented in the model to increase the accuracy of the treatment of ground surfaces and buildings. This treatment of the boundary also allows a user to, without degradation of accuracy, generate simple structured computational grids rather than the complex unstructured computational grids; (2) a bi-conjugate gradients stabilized method (BI-CGSTAB) is used for the Poisson equation solver to increase the numerical efficiency and flexibility since the new boundary treatment and coordinate stretching have made the older solver less efficient; (3) a new initialization method has been applied to ingest the multiple wind profiles from the observations or from a mesoscale numerical weather prediction model; (4) every grid point is geo-coordinated so that the results can be displayed on a GIS software such as Google Map/Earth.

\section{Initialization Procedure}

In many applications, multiple observational or mesoscale model predicted wind profiles are available in a 3DWF microscale model domain. The input of multiple wind profiles can greatly enhance the model results because the microscale wind flow is more chaotic and more variable. We have implemented an objective analysis method that transforms information from randomly spaced observing sites into data at regularly spaced grid points to be used by the model. This objective analysis method is based on an analysis method for complex terrain by Miller and Benjamin [27], which was improved from the original Barnes [28] method. The original Barnes analysis method is:

$f_{A}\left(\mathbf{r}_{i}\right)=\frac{\sum_{k} w\left(d_{i k}, k_{d}\right) f_{0}\left(\mathbf{r}_{k}\right)}{\sum_{k} w\left(d_{i k}, k_{d}\right)}$,

where $f_{A}\left(\mathbf{r}_{i}\right)$ represents the analysis of a variable value at the $\mathrm{i}^{\text {th }}$ location $\mathbf{r}_{i}, f_{0}\left(\mathbf{r}_{k}\right)$ is the $\mathrm{k}^{\text {th }}$ observation value, $w\left(d_{i k}, k_{d}\right)=\exp \left(-d_{i k} / k_{d}\right)$ is the correlation function for the $\mathrm{i}^{\text {th }}$ analysis location and $\mathrm{k}^{\text {th }}$ observation, $d_{i k}$ is the distance between location vectors $\mathbf{r}_{i}$ and $\mathbf{r}_{k}, k_{d}$ is the smoothing factor which defines the radius of influence. As indicated equation (2), the correlation between observational point and analysis point decreases exponentially as the distance between them increases. The Barnes analysis essentially is a 
two-dimensional analysis scheme, which does not consider the reduction of the correlation due to the terrain elevation difference. The Miller and Benjamin [27] analysis, not only uses the horizontal distance in a negative exponent as the correlation function, the elevation differences in the grid points are also accounted for in the correlation function. The correlation function is divided by a factor of $\left(1+C_{z}\left(\Delta Z_{i j}\right)^{2}\right)$ in which the correlation is reduced with respect to the terrain elevation difference, $\Delta Z_{i j}$. $C_{z}$ is a empirical coefficient and it is taken as $7 \times 10^{-6} \mathrm{~m}^{-2}$ in this study. Multiple wind profiles from TODWL observations were ingested for the model initialization. The spatial distribution of the profiles was not in regular spaced grids so the region of the influence, $k_{d}$, was adjusted accordingly to ensure each grid point feed the information from at least one observation. The wind field analysis algorithm was applied to grid the wind observations into every computation point. The object analysis of the irregular observational points over complex terrain is a very difficult problem and it has been a very active research area. We expect to employ the more accurate and efficient analysis method in the future version of the model.

\section{RESULTS}

\section{The Askervein Hill Case}

The first test for the new version 3DWF model is to simulate the wind field over a relatively simple terrain at Askervein Hill in Scotland, UK. There was a very rich data set available from the field campaign organized by Canadian and several European research organizations for the purpose of development of wind energy [29]. Fig. (3) shows the topographic variation of the observational area. The highest point on the hill is $106 \mathrm{~m}$ above mean sea level (AMSL). The lines $\mathrm{A}$ and $\mathrm{B}$ show the observational transits with multiple anemometers. The model domain consists of a 2 by $2 \mathrm{~km}$ area which is the entire observational area. The resolution is $10 \mathrm{~m}$ in both the $\mathrm{x}$ and $\mathrm{y}$ directions, and $2 \mathrm{~m}$ in the vertical. The model grid number is $201 \times 201 \times 101$. The terrain data is in 3 -arcsecond $(\sim 90 \mathrm{~m})$ resolution and was obtained from the Shuttle Radar Topographic Mission (SRTM) [30]. Because the terrain is simple and the slope variation is gentle in every direction, the SRTM can be utilized with small error after interpolation. The data was interpolated to the model grid using a bi-linear interpolation method and the exact latitude and longitude coordinates for

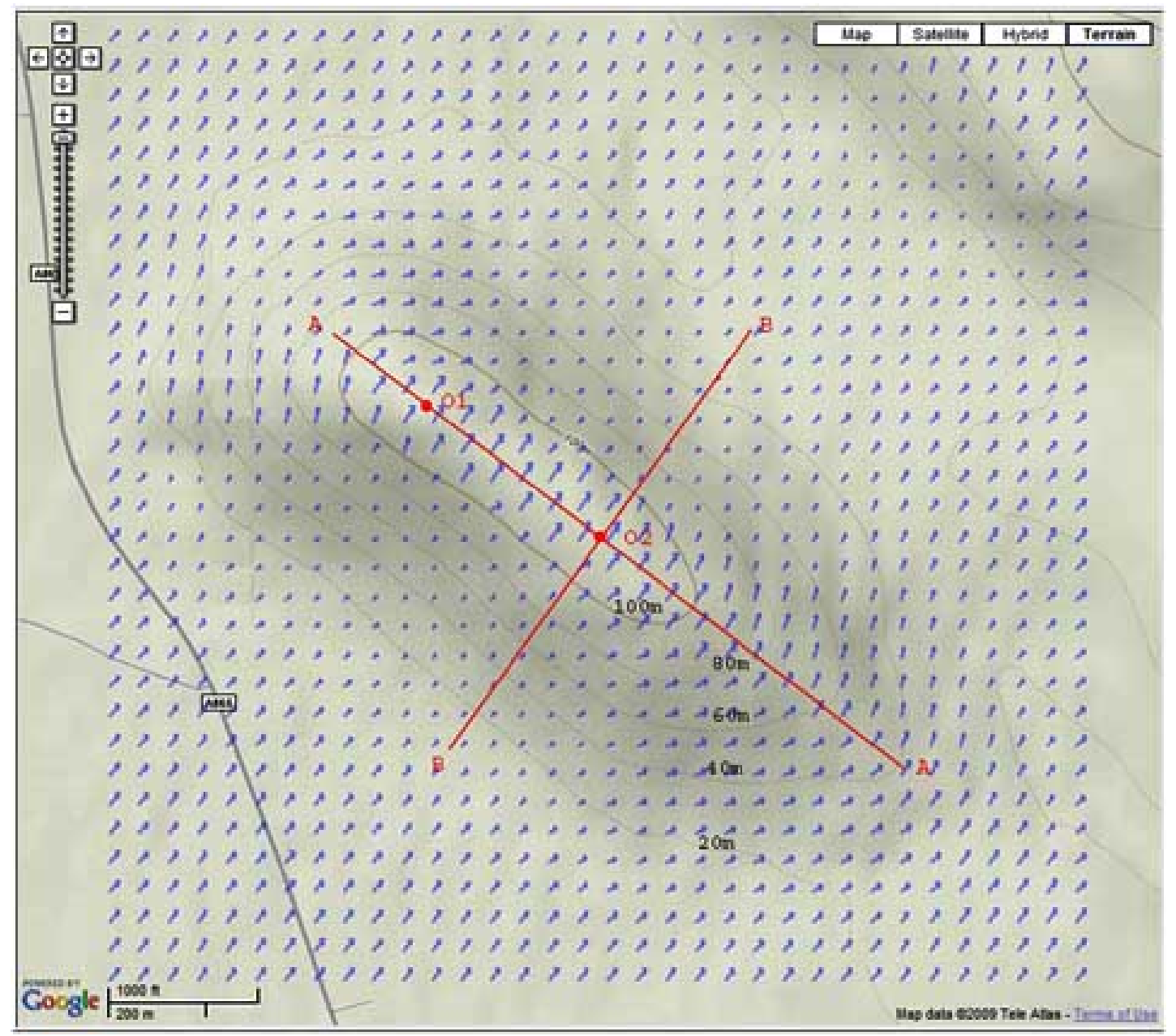

Fig. (3). Horizontal wind at $10 \mathrm{~m}$ above ground level (every $6^{\text {th }}$ vector) from the 3 DWF model. The wind vectors are overlaid over Google map's shaded relief terrain to show the terrain effect on the flow. The terrain elevation is also shown with contour lines. The horizontal resolution $\mathrm{dx}=\mathrm{dy}=10 \mathrm{~m}$ and vertical resolution $\mathrm{dz}=2 \mathrm{~m}$. The anemometer arrays were along the two red lines. The largest wind vector represents the wind of $11.2 \mathrm{~ms}^{-1}$. The shaded relief terrain is from the Google map. 
every grid point were computed from a geodetic algorithm. The model simulation for this case takes about 1.5 minutes CPU time on a $3 \mathrm{GHz}$ PC.

Since the terrain is simple and upwind condition was fairly uniform, the model in this case was initialized with a uniform wind using an upwind profile (MF-27A, [31]) observed in the experiment. This data was collected 0300 to 0430 UTC 27 September 1983. The observed upwind mean wind direction was 235 degrees and speed was $6.1 \mathrm{~ms}^{-1}$ at 10 meter height. Since the wind speed was strong, the atmosphere was in a neutral condition. It is an ideal case for the mass-consistent type model to simulate because the pressure drag due to the hill dominated the flow. We used the standard logarithmic profile with roughness length of $0.03 \mathrm{~m}$ suggested by Taylor Teuinsson [29] to initialize the wind in the entire domain. Fig. (3) also shows the $10 \mathrm{~m}$ above ground level (AGL) wind vectors for the Askervein Hill case. The slow down of the wind in both the upwind and lee sides of the hill are evident in the simulation results. There is a significant speed up ( 1.5 times) at the top of hill. These phenomena are in good agreement with linear analysis of Jackson and Hunt $[32,33]$. The model results at $10 \mathrm{~m}$ above AGL are also compared with the observational array data from the Askervein hill project (Fig. 4). The model gives a good prediction of the wind speed compared with the observations. The first trial of the simulation [26] produced a significantly higher wind speed in a small area at lee side of the hill. This was probably due to the large turbulent production in this area which this type of model is in capable of simulating directly. In this improved simulation, the lee side of the wind is parameterized to slow down the speed before the initialization [24].

The simulation of Askervein Hill indicated that 3DWF performed well in strong and neutral wind conditions, although the terrain was simple compared with most other complex terrains. The domain is also very small and the resolution of the model is very high in order to compare with the observational data. This result, however, does not assure a good model performance in a larger and more complex domain in which the initial wind is not uniform and the terrain elevation difference is much greater than 100 meters.

\section{The Salinas Valley Case with TODWL Initialization}

The Salinas Valley case is much more complex than the earlier Askervein Hill modeling exercise as it encloses multiple heterogeneous hills and valleys throughout the domain. As mentioned previously, the continuous TODWL flight lasted about 4 hours for the entire observation period from 2200 UTC 21 Feb 2003 to 0216 UTC 22 Feb 2003 (Fig. 1). We have divided the entire region into 6 model domains for this simulation study. The 6 domains (see Fig. 5) are identical in domain size (401 X $401 \times 201$ grid points) and in resolution $(\mathrm{dx}=\mathrm{dy}=50 \mathrm{~m}$, and $\mathrm{dz}=10 \mathrm{~m})$. The elevation difference from lowest to highest point is less than $850 \mathrm{~m}$ within all of the simulation domains. There are several rationales to having multiple simulation domains in this study. First, the entire TODWL flight area is too large to be enclosed in one domain if reasonably high spatial resolution is desired. Second, and more importantly, this type of diagnostic model is designed to model the wind in a relatively short time window, and four hours would be too long for that purpose. Third, the National Weather Service (NWS) standard surface observation is recorded hourly and the surface wind data is used to validate the model. The red balloon marks in Fig. (5) denote the location of each NWS surface station. Each domain was designed to include two surface stations. The terrain is interpolated to a $50 \mathrm{~m}$ grid using a bilinear interpolation method.

The number of TODWL retrieved wind profiles in each simulation domains (Table 2) was significantly different. The spatial distribution of those profiles was also quite different (Fig. 1) among the domains, with more uniform distribution in domains 4 and 2. This profile distribution may affect the quality of the initial wind field analysis. The objective analysis algorithm described in the method section was applied to grid the wind data over the complex terrain. Since each domain had a different lidar wind profile distribution, the influence radius in the objective analysis was varied accordingly with larger radius values in sparse
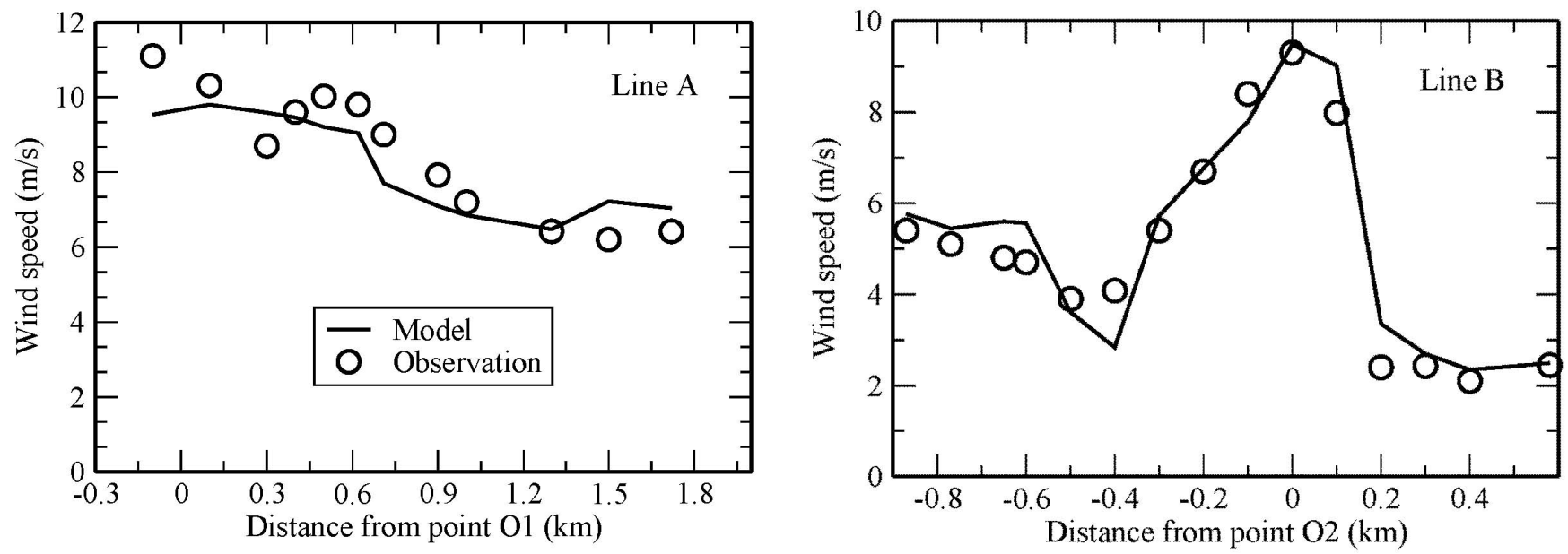

Fig. (4). Comparison of the modeled horizontal wind speed with the observations over line A and line B (see Fig. 3) over the Askervein Hill at $10 \mathrm{~m}$ AGL. The zero points (O1 and $\mathrm{O} 2)$ are denoted in Fig. (3). 


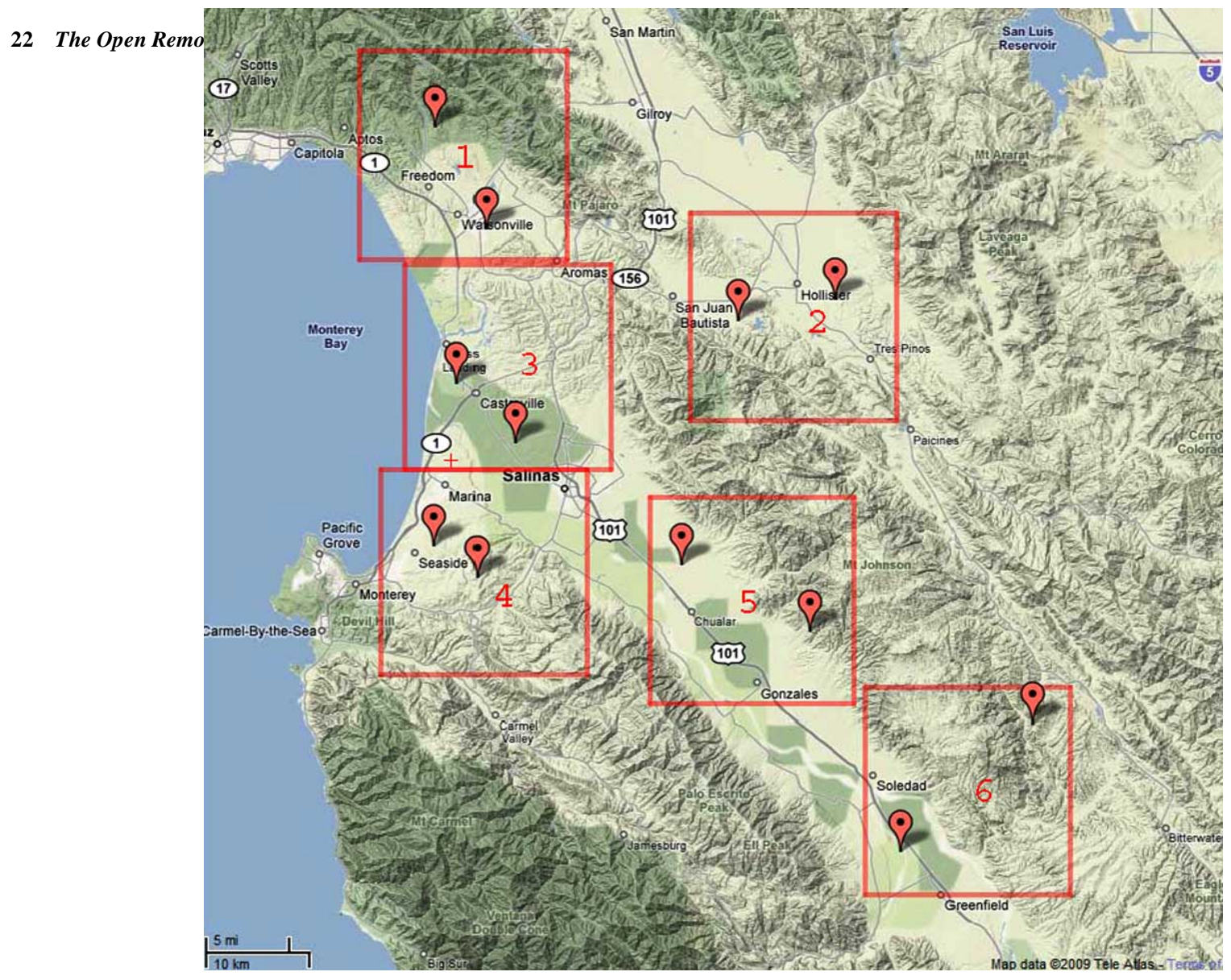

Fig. (5). The model simulation domains (red squares). Each simulation domain includes two NWS surface observation sites (red balloon markers). Each domain encompasses a $20 \mathrm{~km} \mathrm{X} 20 \mathrm{~km}$ area. The resolution and grid numbers are the same for each domain $(\mathrm{dx}=\mathrm{dy}=50 \mathrm{~m}$, $\mathrm{dz}=10 \mathrm{~m}, 401 \mathrm{X} 401 \mathrm{X} 201)$. The red + sign in domain 3 is the location of the radar wind profiler operated by the U. S. Navy Postgraduate School. The terrain is Google shaded relief map.

situations and much smaller values in dense and uniform situations. The elevation data was derived from the USGS 1 arcsecond ( $\sim 30 \mathrm{~m}$ resolution) national elevation data set using a bi-linear interpolation algorithm. The near surface wind from 0 to $50 \mathrm{~m}$ was extrapolated downward with a neutral logarithmic wind profile with roughness length of $0.05 \mathrm{~m}$. It took about 3.5 minutes for the $3 \mathrm{DWF}$ to simulate a wind field cube in each domain using a $3 \mathrm{GHz}$ PC.

Table 2. Number of TODWL Profiles Used for Initialization Analysis

\begin{tabular}{|l|l|l|}
\hline Domain Numbers & $\begin{array}{l}\text { Number of TOWDL } \\
\text { Profiles }\end{array}$ & $\begin{array}{l}\text { Radius (km) of } \\
\text { Influence in } \\
\text { Objective Analysis }\end{array}$ \\
\hline \hline Domain 1 & 14 & 12 \\
Domain 2 & 25 & 10 \\
Domain 3 & 12 & 11 \\
Domain 4 & 36 & 10 \\
Domain 5 & 12 & 15 \\
Domain 6 & 7 & 20 \\
\hline
\end{tabular}

Fig. (6) shows the simulation results for the surface wind (at $10 \mathrm{~m}$ AGL) for domain 6. The wind over the Salinas valley area for the lower left domain is fairly uniform due to the absence of blocking and interaction of the mountains.
The simulated winds over the mountainous area show large variations both in direction and speed. The simulation results show the effects of channeling and blocking which increases speed at mountain tops and strongly reduces speed in small canyons. It is also seen that the wind directions have significant changes in the mountainous areas, but very little change in the flat Salinas valley. NWS surface observations (blue vectors enclosed in blue circles for clarity) at the same hour had fairly good agreement with the simulation in this case. The other domains show similar terrain effects on the near surface wind.

The comparison of NWS surface observations with the nearest simulations is shown is Fig. (7). Those model results were selected from the nearest points using the NWS surface station latitude and longitude coordinates. Generally, the wind speed shows reasonably good agreement between the NWS surface station data and the model results. The wind directions, however, are problematic in the low speed condition. Two weak wind speed observation points located in domain 1 (marked with red 1 and 2 in Fig. 7) showed more than 100 degree differences between the observations and the model results. Excluding the low wind speed values, the correlation coefficient between the observation and the model is 0.68 for horizontal wind speeds, and 0.78 for wind directions. The correlation coefficient for wind directions decreases to 0.15 if two low speed values are included, while 


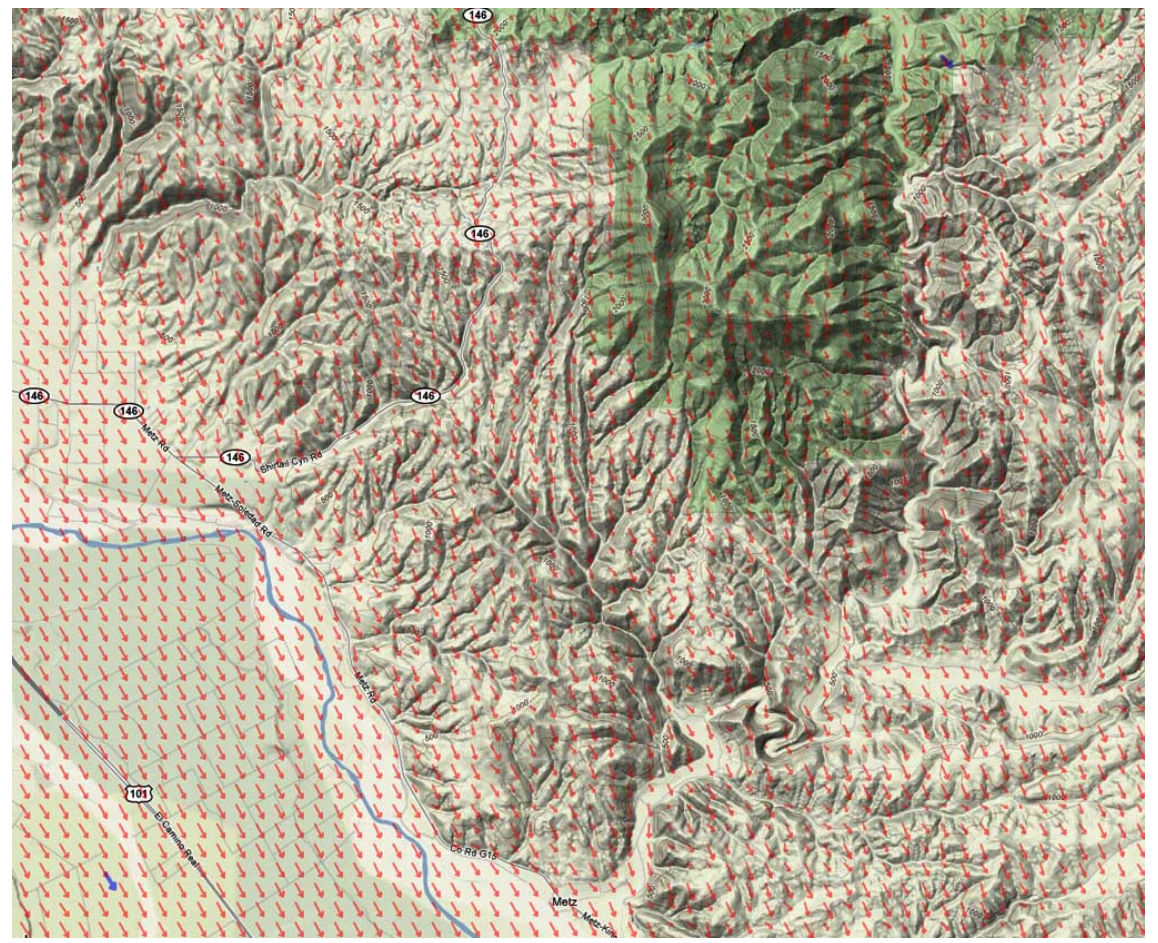

Fig. (6). 3DWF model simulated surface wind field at $10 \mathrm{~m}$ AGL in domain 6 (red arrows, every $6^{\text {th }}$ wind vector is plotted). The blue vectors are the two NWS surface observations overlaid on the Google map. The magnitude of the largest wind vector is $8.7 \mathrm{~ms}^{-1}$.
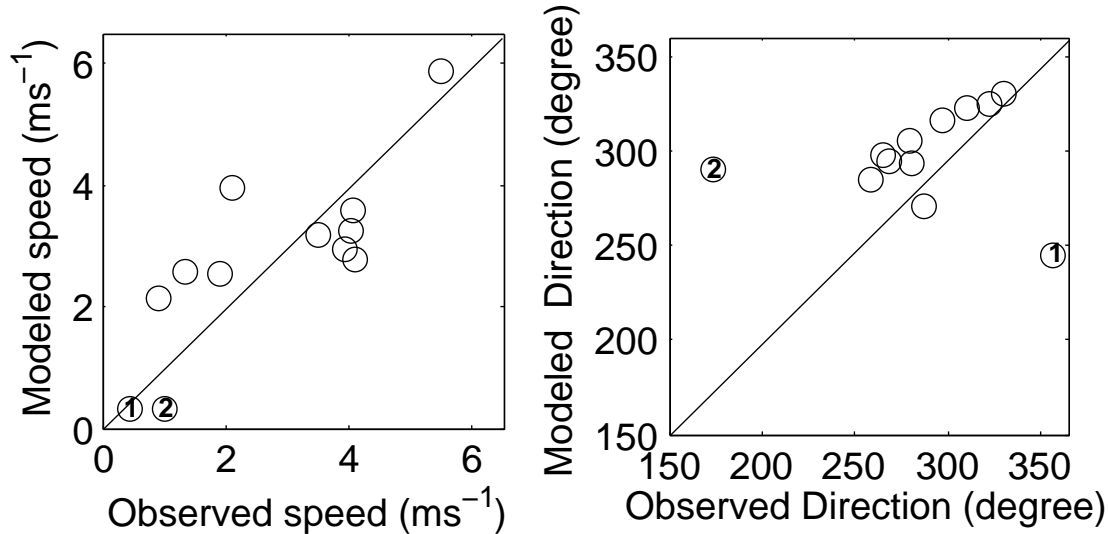

Fig. (7). Comparison of the model produced 10m AGL wind with the NWS observation results. The left panel is for the wind speeds, and the right panel is for the wind directions. Note the two marked data points ( 1 and 2 ) indicated the low wind speed and large deviation of wind directions compared with the observation.

the correlation coefficient for wind speed does not change much (0.80) if two low speed values are included. This result points out the deficiency of the diagnostic mass consistent wind model in weak wind conditions, in which the surface driven thermal circulation dominates the flow. This limitation is rooted in the equation set of the diagnostic wind model, in which the thermal equation is not included. In the moderate to strong wind conditions, the transport of momentum from upper levels dominates the flow and is probably the reason that the model performed better in stronger wind conditions.

The wind observations at higher elevations are also compared with the model results. At the higher altitudes, the wind field distribution is generally more uniform compared with that near the surface. The wind at these heights is more likely controlled by the large scale weather system. Fig. (8) shows a comparison of the model results with the Navy Postgraduate School microwave wind profiler radar data. The 3DWF wind model was initialized with the TODWL observations from 0000 to 0001 UTC 22 February 2003 data. Two profiles from the microwave wind profiler are shown, each being representative of a half hour average. Overall, the model results at higher level $(>400 \mathrm{~m})$ compared fairly well with the profiler observations. The lower levels, however, do show large wind direction differences. The wind profiler data showed much more drastic wind direction changes, while the model results produced a gradual shift of wind direction. Given the fact that the initial TODWL data and radar wind profiler sampled different volumes of air (the largest sample volume for TODWL was near surface while smallest sample volume was near surface for the wind profiler), the larger difference between two observations near the surface is expected. 

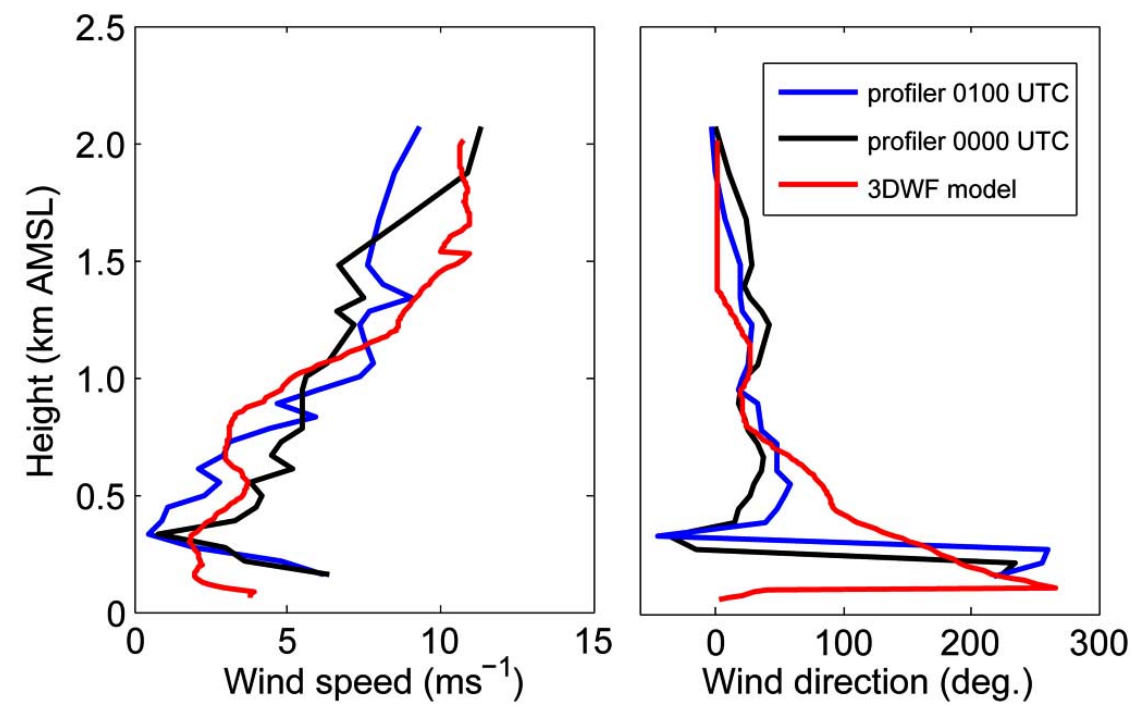

Fig. (8). Comparison of the model simulation results with a microwave wind profiler near the Fort Ode area. The 3DWF wind model is initialized with the TODWL observations from 0000 to 0001 UTC 22 Feb 2003 data. Two profiles from the microwave wind profiler are shown.

\section{Data Density Effects on the Model Results}

The above model initialization exercise used a different number of profiles (Table 2) and a different profile spatial distribution for each domain. A question to be asked is how many profiles are needed in order to obtain a reasonable wind field simulation in a domain of this size and terrain complexity. This subject is investigated by an analysis of the simulation results from a simple data thinning experiment.

In the Askervein hill case, the terrain is shaped approximately as a half-ellipsoid and the domain is small. Given the comparison of model results with observations in that case, there is evidence that one upwind profile is sufficient for the model initialization. However, for the Salinas valley case, the domain is relatively large and the terrain consists of multiple mountain peaks with complex variations. More representative wind profiles are required to capture the spatial variations of the initial wind field. The wind in the Salinas valley case was dominated by a low level sea-breeze and sudden clockwise veer of wind direction in upper levels. The wind field variation was not very significant from $1000 \mathrm{~m}$ above sea level. The wind speed and direction at lower levels did show significant variations [22]. Obviously, representative observational profiles of the terrain feature are important and uniform distribution of the profiles is preferred for the initialization but, in reality, a careful planning of the flight tracks is required to satisfy this criteria.

In the current Salinas Valley case, the data thinning experiment was performed on domain 4. Domain 4 was utilized because it has the largest number of the TODWL profiles used in the initialization process as well as the most uniform distribution of profiles (Fig. 1). The profiles were thinned by gradually reducing the number of profiles. Every other profile was taken out in the process of reducing the profile density. The number of profiles was reduced from 36 (original number) to 18,9 , and 6. Fig. (9) shows the sensitivity of the $10 \mathrm{~m}$ AGL wind to the number of TODWL initial profiles in domain 4 . The general flow patterns were not very sensitive to the number of initial profiles. The wind field differences are gradually increased as the number of initial wind profiles decreased from 36 to 6 . The wind speeds in the northwest part of the domain showed larger differences than those in other regions while the wind field in the more complex terrain regions showed wind fields forced by the terrain features. This experiment indicated that over a half dozen initial wind profiles were probably adequate for this domain in this kind of mesoscale wind condition. This sensitivity test result should be interpreted with some caution since the wind field did not have much variation in this domain. The sensitivity to the number of initial profiles is probably related to the larger scale weather pattern and to the complexity of the terrain. When a strong flow feature such as a mesoscale vortex, mountain valley flow, or land-sea breeze flow, is present in a domain, more initial profiles are likely needed for a good initial wind field.

Fig. (10) shows a wind field in domain 4 at $0.8 \mathrm{~km}$ AMSL with a 36 profile initialization. The wind field at $0.8 \mathrm{~m} \mathrm{~km}$ displayed much more uniform flow except at the locations where the terrain is very high. The southeast quadrant of the domain shows that the flow was deflected by the terrain features. It is worthwhile to compare the model results at the upper levels with the TODWL observed wind profiles in this sensitivity test. To maintain a certain degree of independence, those lidar profiles "thinned out" in the experiment have been used in the comparison. The red balloons in Fig. (10) are the four locations where the wind profiles were taken for the purpose of comparison. Fig. (11) shows the vertical profiles comparisons of TODWL and model results at points $\mathrm{A}, \mathrm{B}, \mathrm{C}$, and $\mathrm{D}$ respectively. The number 1 profiles at each point were from the TODWL observation, the number 2,3 , and 4 profiles were sampled every $50 \mathrm{~m}$ (the TODWL vertical resolution) from the different model simulations with different numbers of initial profiles $(18,9,6$ initial profiles) respectively. The model results show reasonable agreement with the TODWL observations except at or near the terrain surface. It is also seen that the modeled wind profiles resulting from different 

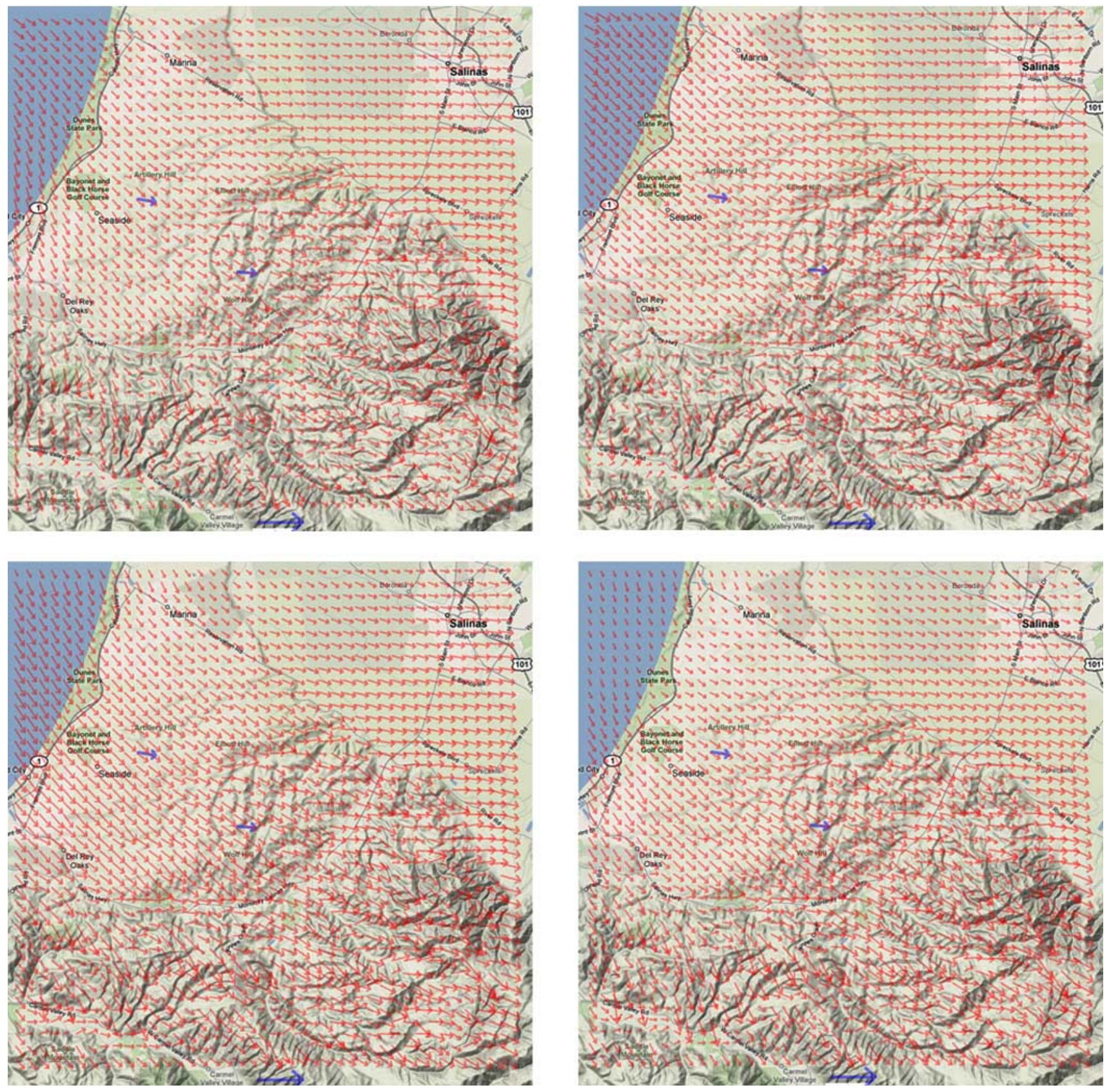

Fig. (9). The sensitivity of $10 \mathrm{~m}$ AGL wind field to number of TODWL profiles in initialization for domain 4 . Each $10^{\text {th }}$ vector is shown for clarity. Top left: 36 profiles; Top right: 18 profiles; Bottom left: 9 profiles; Bottom right: 6 profiles. Two blue arrows are from the NWS surface wind observations. Horizontal long blue arrow at bottom of the domain is the $10 \mathrm{~ms}^{-1}$ wind speed scale. The shaded relief terrain is from the Google map.

numbers of initial profiles are not very different. The results indicated that more than a half dozen lidar wind profiles would be adequate for a 20 by $20 \mathrm{~km}$ complex terrain domain for this fairly uniform and moderate wind condition.

\section{SUMMARY AND CONCLUSION}

An improved version of the 3DWF model has been described with more accurate boundary treatment, the new Poisson solver, and an initialization procedure. The model was first tested with a simple terrain and a small domain, the
Askervein hill case. The model gives a good diagnostic wind field for the simple Askervein hill case using observational data for a strong wind condition. The result indicates that a single upwind profile initialization is probably adequate for a small domain $(\sim 2$ by $2 \mathrm{~km})$ with simple terrain in strong wind conditions.

A new method of initialization using the airborne DWL data was developed and evaluated for a diagnostic wind model for a large domain ( 20 by $20 \mathrm{~km}$ ). The wind profile retrieval algorithm used for the TODWL data computes wind 


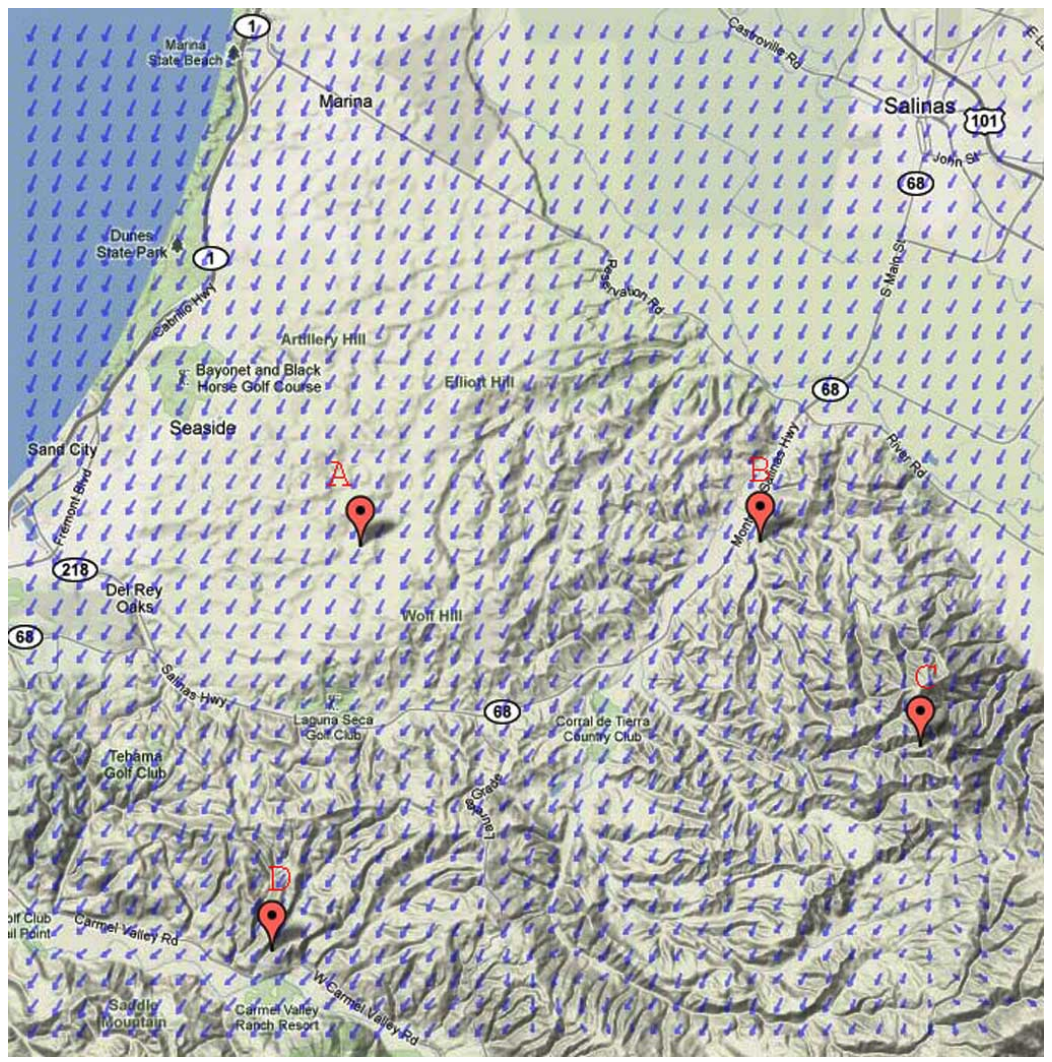

Fig. (10). The wind field at $0.8 \mathrm{~km}$ height above mean sea level for domain 4 with 36 initial profiles. The highest peak is at the southeast corner of the domain which is $0.81 \mathrm{~km}$. Each $10^{\text {th }}$ vector is shown. The markers A, B, C, and D are the locations for the vertical profiles comparisons shown in Fig. (11). The shaded relief terrain is from the Google map.

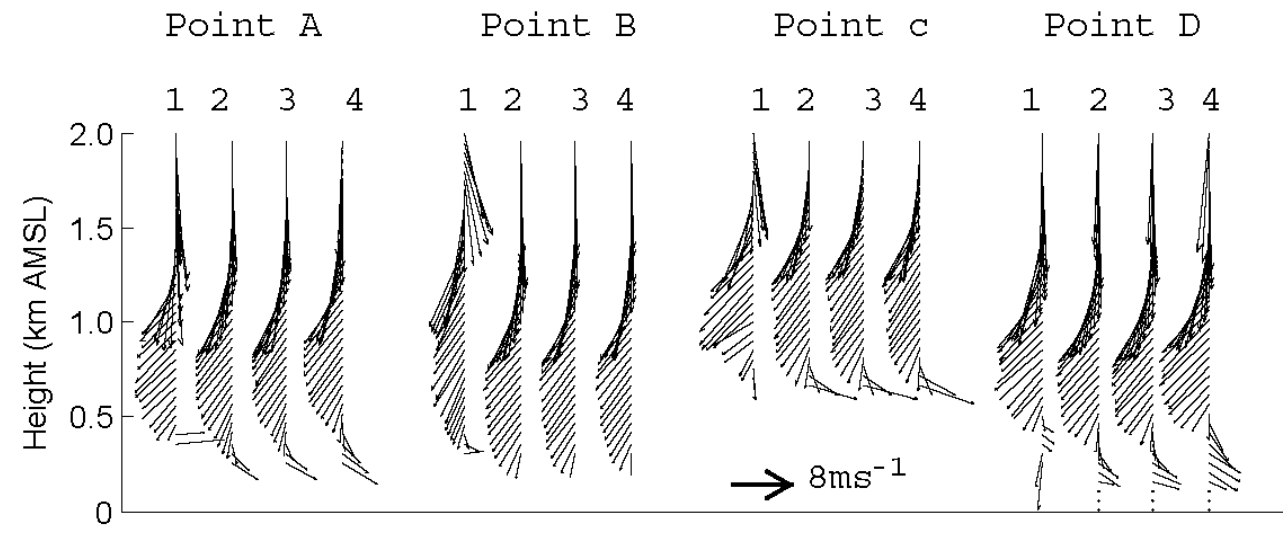

Fig. (11). The comparison of 3DWF model output with the TODWL lidar profiles at selected points A, B, C and D (see Fig. 10 for locations). The TODWL profiles displayed are not used for initialization. For each point, vector profile 1 is from a TODWL observation; vector profile 2 is the 3DWF result using 18 initial profiles; profile 3 is the 3DWF result using 9 initial profiles; profile 4 is the 3DWF result using 6 initial profiles.

components based on the VAD method and corrects for errors due to the movement of aircraft. The information from DWL profiles was then distributed via an objective analysis method for complex terrain. The model results using the lidar data were compared with independent observational data sets from NWS surface stations and from a co-located radar wind profiler. The analysis indicated that the model performed reasonably well using this initialization technique in moderate to strong wind conditions. However, large differences were seen in wind directions near the terrain surface in weak wind conditions, in which the mass- consistent diagnostic wind model is known to be problematic. Given the capability of airborne DWL which can cover a large data void area within short time period, plus the very fast computational speed of the diagnostic wind model, the combination of the two components has very good potential for many near real-time applications.

The data density effect on the model results was also investigated by conducting data thinning experiments. The modeled wind profiles show that the model results are not very sensitive to the total number of wind profiles down to 6 profiles, the required density. This required density is most 
likely related to how uniform the wind and how complex the terrain is in the domain. The results indicate that more than a half dozen lidar wind profiles would be adequate for a 20 by $20 \mathrm{~km}$ complex terrain domain for this fairly uniform and moderate wind condition.

\section{ACKNOWLEDGEMENTS}

We would like to acknowledge the Air Force Weather Agency for their support in part of this research and development. We also acknowledge the Office of Naval Research and the Integrated Program Office of the National Polar orbiting Operational Environmental Satellite System which funded the TODWL flights that collected the data used in this study.

\section{REFERENCES}

[1] Post MJ, Neff WD. Doppler lidar measurements of winds in a narrow mountain valley. Bull Am Meteorol Soc 1986; 67: 274-81.

[2] Banta RM, Darby LS, Kaufmann P, Levinson DH, Zhu C. WindFlow patterns in the grand canyon as revealed by doppler lidar. J Appl Meteorol 1999; 38: 1069-83.

[3] Banta RM, Olivier LD, Levinson DH. Evolution of the monterey bay sea-breeze layer as observed by pulsed Doppler lidar. J Atmos Sci 1993; 50: 3959-82.

[4] Darby LS, Banta RM, Pielke RA. Comparisons between mesoscale model terrain sensitivity studies and doppler lidar easurements of the sea breeze at Monterey Bay. Mon Wea Rev 2002; 130: 281338 .

[5] Banta RM, Pichugina YL, Newsom R K. Relationship between low-level jet properties and turbulence kinetic energy in the nocturnal stable boundary layer. J Atmos Sci 2003; 60: 2549-55.

[6] Newsom RK, Banta RM. Shear-flow instability in the stable nocturnal boundary layer as observed by doppler lidar during CASES-99. J Atmos Sci 2003; 60: 16-33.

[7] Calhoun R, Heap R, Princevac M, Newsom R, Fernando H, Ligon D. Virtual towers using coherent doppler lidar during the Joint Urban 2003 Experiment. J App Met 2006; 45:1116-26.

[8] Wang Y, Klipp C, Garvey D, et al. Nocturnal low-level-jet dominated atmospheric boundary layer observed by doppler lidars over Oklahoma city during JU 2003. J Appl Met Clim 2007;46: 2098-09.

[9] Chai T, LIN C-L, Newsom R. Retrieval of microscale flow structures from high-resolution doppler lidar data using an adjoint model. J Atmos Sci 2004; 61: 1500-20.

[10] Newsom RK, Ligon D, Calhoun R, Heap R, Cregan E, Princevac M. Retrieval of microscale wind and temperature fields from single- and dual-doppler lidar data. J App Meteorol 2005; 44:132445 .

[11] Emmitt D, O'Handley C, Wood SA, Bluth R, Jonsson H. TODWL: an airborne doppler wind lidar for atmospheric research. Annual AMS Conference, $2^{\text {nd }}$ Symposium on Lidar Atmospheric Applications. San Diego, CA January 2005.

[12] Greco S, Emmitt GD, Wood S, O'Handley C, Jonsson H. Synergisms and comparisons between airborne Doppler Wind Lidar observations and other remote and in-situ wind measurements and model forecasts, Proc. of the Annual Amer. Met. Soc. Conference, 12th Conference on IOAS-AOLS, New Orleans, LA 2008.
[13] Weissmann M, Busen R, Dörnbrack A, Rahm S, Reitebuch O. Targeted observations with an airborne wind lidar. J Atmos Oceanic Technol 2005; 22: 1706-19.

[14] Sasaki Y. Some basic formalisms in numerical variational analysis. Mon Wea Rev 1970; 98:875-83.

[15] Sherman CA. A mass-consistent model for wind field over complex terrain. J Appl Meteorol 1978; 17:312-19.

[16] Davis CG, Bunker SS, Mutschlecner JP. Atmospheric transport models for complex terrain. J. Clim Appl Meteorol 1984; 23: 23538 .

[17] Kitada T, Igarashi K, Owada M. Numerical analysis of air pollution in a combined field of land/sea breeze and mountain/valley wind. J Clim Appl Meteorol 1986; 25: 767-84.

[18] Ross DG, Smith IN, Manins PC, Fox DG. Diagnostic wind field modeling for complex terrain: model development and testing. J Appl Meteorol 1988; 27: 785-96.

[19] Venkatesan R, Mollmann-Coers M, Ntarajan A. Modeling wind field and pollution transport over a complex terrain using an emergency dose information code SPEEDI. J Appl Meteorol 1997; 36: $1138-59$.

[20] DTRA The HPAC User's Guide. Hazard Prediction and Assessment Capability, Version 4.0, 605 US Defense Threat Reduction Agency 2001; p. 605.

[21] Scire JS, Robe FR, Fernau MF, Yamartino RJ. A user guide for CALMET Meteorological model. Earth Tech Inc. Concord, MA 2000.

[22] Greco S, Emmitt G D. Investigation of flows within complex terrain andalong coastlines using an airborne Doppler wind lidar: Observations and model comparisons Annual Amer. Met. Soc.Conference, Sixth Conference on Coastal Atmospheric and Oceanic Prediction and Processes, San Diego, CA January 2005.

[23] Browning KA, Wexler R. The determination of kinematic properties of a wind field using Doppler radar. J Appl Meteorol 1968; 7:105-13.

[24] Wang Y, Williamson C, Garvey D, Chang S, Cogan J. Application of a multigrid method to a mass consistent diagnostic wind model. J App Meteorol 2005; 44: 1078-89.

[25] Wang Y, Cionco R. Wind profiles in gentle terrains and vegetative canopies for a 3D wind field model. ARL Tech Report -4178; 2007.

[26] Wang Y, Williamson C, Emmitt D, Greco S. An improved diagnostic wind model and its initialization using the airborne doppler wind lidar data. AMS $4^{\text {th }}$ Symposium on Lidar Atmospheric Applications. Phoenix, AZ 2009.

[27] Miller PA, Benjamin SG. A system for the hourly assimilation of surface observations in mountainous and flat terrain. Mon Wea Rev 1992; 120: 2342-59.

[28] Barnes S L. A technique for maximizing details in numerical weather map analysis. J Appl Meteorol 1964; 3: 394-09.

[29] Taylor PA, Teunissen HW. The Akervein hill project: overview and background data. Boundary-layer Meteorol 1987; 39: 15-39.

[30] Farr TG, Rosen P, Caro E, et al. The shuttle radar topography mission. Rev Geophys 2007; 45: RG2004.

[31] Taylor PA, Teunissen HW. The Akervein hill project: Report on the Sept./Oct. 1983, Main field experiment. Canada Atmospheric Environ Service, Environment 1985.

[32] Hunt, JCR, Leibovich S, Richards KJ. Turbulent shear flow over low hills. Quart J Roy Meteorol Soc 1988;114: 1435-70.

[33] Jackson PS, Hunt JCR. Turbulent wind flow over a low hill. Quart J Roy Meteorol Soc 1975; 101: 929-55.

(c) Wang et al.; Licensee Bentham Open.

This is an open access article licensed under the terms of the Creative Commons Attribution Non-Commercial License (http://creativecommons.org/licenses/by-nc/3.0/) which permits unrestricted, non-commercial use, distribution and reproduction in any medium, provided the work is properly cited. 